Published in final edited form as:

Nat Nanotechnol. 2019 March ; 14(3): 260-268. doi:10.1038/s41565-018-0344-3.

\title{
Immunoglobulin deposition on biomolecule corona determines complement opsonisation efficiency of preclinical and clinical nanoparticles
}

\author{
Vivian P. Vu ${ }^{1}$, Geoffrey B. Gifford ${ }^{1}$, Fangfang Chen $^{2}$, Halli Benasutti ${ }^{1}$, Guankui Wang ${ }^{1,3}$, \\ Ernest V. Groman ${ }^{1,3}$, Robert Scheinman ${ }^{3}$, Laura Saba ${ }^{4,5}$, Seyed Moein Moghimi ${ }^{3,6,7}$, and \\ Dmitri Simberg $1,3,1$ \\ ${ }^{1}$ Translational Bio-Nanosciences Laboratory, The Skaggs School of Pharmacy and \\ Pharmaceutical Sciences, Department of Pharmaceutical Sciences, University of Colorado \\ Anschutz Medical Campus, Aurora, CO 80045, USA \\ ${ }^{2}$ Department of Gastrointestinal Surgery, China-Japan Union Hospital, Jilin University,, \\ Changchun, Jilin, 130033, China
}

${ }^{3}$ Colorado Center for Nanomedicine and Nanosafety, University of Colorado Anschutz Medical Campus, Aurora, CO 80045, USA

${ }^{4}$ Systems Genetics and Bioinformatics Laboratory, The Skaggs School of Pharmacy and Pharmaceutical Sciences, Department of Pharmaceutical Sciences, University of Colorado Anschutz Medical Campus, Aurora, CO 80045, USA

${ }^{5}$ Center for Translational Pharmacokinetics and Pharmacogenomics, University of Colorado Anschutz Medical Campus, Aurora, CO 80045, USA

${ }^{6}$ School of Pharmacy, The Faculty of Medical Sciences, King George VI Building, Newcastle University, Newcastle upon Tyne NE1 7RU, UK

${ }^{7}$ Division of Stratified Medicine, Biomarkers \& Therapeutics, Institute of Cellular Medicine, Newcastle University, Framlington Place, Newcastle upon Tyne NE2 4HH, UK

\section{Abstract}

Deposition of complement factors (opsonisation) on nanoparticles may promote clearance from the blood by macrophages and trigger proinflammatory responses, but the mechanisms regulating the efficiency of complement activation are poorly understood. We previously demonstrated that

Users may view, print, copy, and download text and data-mine the content in such documents, for the purposes of academic research, subject always to the full Conditions of use:http://www.nature.com/authors/editorial_policies/license.html\#terms

${ }^{1}$ Correspondence and requests for materials should be addressed to D.S.

Author contributions

V.P.V., F.C., H.B., E.V.G., G.B.G. and G.W. performed the experiments. R.S., L.S., S.M.M. and D.S. analysed the data. S.M.M. and D.S. conceived the experiments and wrote the manuscript.

Additional information

Supplementary information is available in the online version of the paper. Reprints and permissions information is available online at www.nature.com/reprints.

Competing financial interests

The authors declare no competing financial interests. 
opsonisation of superparamagnetic iron oxide nanoworms (SPIO NWs) with the third complement protein (C3) was dependent on the biomolecule corona. Here we show that natural antibodies play a critical role in $\mathrm{C} 3$ opsonisation of SPIO NWs and a range of clinically approved nanopharmaceuticals. The dependency of $\mathrm{C} 3$ opsonisation on immunoglobulin binding is predominantly universal and is observed regardless of the complement activation pathway. Few surface-bound immunoglobulin molecules trigger complement activation and opsonisation. While the total amount of nanoparticle-absorbed protein does not determine C3 deposition efficiency, the biomolecule corona per se enhances immunoglobulin binding to all nanoparticle types. We therefore show that natural antibodies represent a link between biomolecule corona and C3 opsonisation, and may determine individual complement responses to nanomedicines.

\section{Keywords}

complement; immunoglobulin; nanoparticle; biomolecule corona; opsonisation; SPIO; liposome; iron oxide; Doxil

Significant advances in development of engineered nanomaterials have resulted in several nanopharmaceuticals for clinical use and many more in clinical development stage. ${ }^{1}$

Nevertheless, there are still important issues that need to be resolved, including non-specific clearance of functional nanoparticles by different immune cell types and life threatening infusion reactions that occur in some patients receiving nanopharmaceuticals. ${ }^{2}$ Better understanding of immune mechanisms that lead to the clearance and toxicities of nanomaterials in general, and of clinically approved nanopharmaceuticals in particular, should be one of the primary tasks in nanomedicine research and development. Plasma protein adsorption has long been debated to be an important factor affecting functionality of intravenously injected nanomedicines. ${ }^{3,4,5}$ Recent studies have demonstrated the role of absorbed proteins in nanoparticle targeting, ${ }^{6}$ immune responses, ${ }^{7}$ and intracellular toxicity. 8, 9 Among the most interesting immunological constituents of protein corona are components of the complement system. Upon activation, all three pathways (alternative, classical, and lectin) of the complement system converge at point where the third complement protein (C3) is cleaved through assembly of $\mathrm{C} 3$ convertases, which generate a common set of effector molecules including C3a and C3b. ${ }^{2,10}$ The latter fragment covalently bind to activating surfaces thereby facilitating their recognition by leukocytes and macrophages; a process termed opsonisation. C3b is further involved in surface assembly of C5 convertase that in turn cleaves the fifth complement protein (C5) into C5a and C5b, thereby triggering activation of the terminal pathway of the complement system. Both C3a and C5a are potent anaphylatoxins, which activate mast cells and other immune cells, and therefore induce proinflammatory reactions. While the role of complement in infusion reactions to nanomedicine is being debated, ${ }^{11}$ there is a concern that uncontrolled complement activation may affect the disease outcome and nanomedicine performance in general. $^{12,13,14}$

Since opsonisation with C3 is the central event in complement cascade and immune recognition, mechanisms of $\mathrm{C} 3$ deposition on nanomedicines are of special interest for biological performance. ${ }^{2}$ Earlier we found that $\mathrm{C} 3 \mathrm{~b}$ preferentially binds to the biomolecule 
corona on superparamagnetic iron oxide nanoworms (SPIO NWs) in both plasma and sera. Moreover, C3 deposition was significantly enhanced in the presence of protein corona, underlying the dependence of the complement activation on other, less characterised corona components. ${ }^{15}$ SPIO is an important magnetic resonance imaging contrast agent and a component of multifunctional theranostic nanomedicines for imaging and treatment. ${ }^{16,17}$ Furthermore, we demonstrated a significant between-subject variability in levels of C3 deposition on SPIO NWs, as well as clinically approved nanomedicines including intravenous iron supplement Feraheme ${ }^{\circledR}$, PEGylated liposomal doxorubicin LipoDox ${ }^{\circledR}$ and non-PEGylated liposomal irinotecan Onivyde ${ }^{\circledR} .18$ We hypothesise that complement activation efficiency by these nanomaterials is determined by differences in biomolecule corona composition. Among many plasma proteins, natural antibodies such as IgG and IgM are known to bind to foreign and self-antigens, and modulate complement activation through the three complement pathways. ${ }^{19,20,21,22}$ Here we demonstrate that binding of only a few immunoglobulin molecules, and specifically $\mathrm{IgG}$, determines the efficiency of C3 deposition on the above-mentioned nanomaterials in plasma and sera of healthy donors and in plasma of cancer patients, regardless of the complement activation pathway. Moreover, we demonstrate that the presence of the biomolecule corona enhances IgG binding to all tested nanomaterials. These results establish natural antibodies as a critical factor that determines the efficiency of complement activation in different subjects and by different nanomaterials and can promote development of clinically approved nanoparticles with improved safety profile.

\section{Immunoglobulins promote C3 deposition on nanomedicines}

We prepared $\sim 110 \mathrm{~nm}, 20 \mathrm{kDa}$ dextran-coated SPIO NWs (Fig. 1a and Supplementary Table 1) as described previously. ${ }^{15,23}$ In order to understand the role of immunoglobulins in $\mathrm{C} 3$ deposition on NPs, we pretreated lepirudin plasma of 3 healthy donors with protein A sepharose beads. Protein A strongly binds human IgG, but weakly binds human IgM. Following this pretreatment, there was minimal detectable level of immunoglobulin in plasma, but the quantities of C1q and C3 were close to physiological levels (Supplementary Fig. S1). According to Western blot analysis (Fig. 1b and Supplementary Fig. S2), the deposition of $\mathrm{C} 3$ (predominantly iC3b) on NWs was decreased in all depleted plasma, and addition of polyclonal human IgG restored C3 deposition. Compared with Western blot, dot blot is a more quantitative assay to measure changes in deposition of proteins on nanoparticle surface (Supplementary Fig. S3). ${ }^{15,18,23,24}$ Again, dot blot analysis in sera of 7 healthy donors (Fig. 1c) not only confirmed a significant decrease in C3 opsonisation in depleted sera $(p<0.0001)$, but also a significant increase in C3 opsonisation $(p<0.0001)$ upon addition of polyclonal human IgG. Since protein A can potentially deplete some IgM, we tested the ability of purified polyclonal IgM to restore complement C3 deposition. Addition of IgM to three protein A-depleted sera only marginally increased the level of C3 deposited on SPIO NWs (Supplementary Fig. S4). Also, addition of a monoclonal human IgG (trastuzumab) to the depleted sera had no significant effect on C3 deposition (Fig. 1d). Lastly, measurement of bound immunoglobulin and C3 in sera of 12 healthy subjects ( 7 females and 5 males) showed a significant association between levels of immunoglobulin 
and C3 (Fig. 1e, $p=0.0002$ ). These data suggest that immunoglobulins, in particular IgG class, play an important role in the efficiency of complement C3 deposition on SPIO NWs.

Surface absorbed antibodies can promote $\mathrm{C} 3$ opsonisation through all three complement pathways (Fig. 1f). The classical pathway involves C1q binding to the Fc portion of closely adjacent antibodies, ${ }^{25}$ whereas the lectin pathway may be triggered via binding of mannosebinding lectin, collectins and ficolins to sugar residues on $\operatorname{IgG} .{ }^{26,27} \mathrm{In}$ addition to these, $\mathrm{IgG}$ can enhance $\mathrm{C} 3$ deposition directly by acting as a scaffold for initial C3b binding and subsequently amplify $\mathrm{C} 3 \mathrm{~b}$ deposition through the alternative pathway turnover. ${ }^{20,21} \mathrm{C} 3$ deposition in plasma of 3 donors (same donors as in Fig. 1b) was not inhibited by the classical pathway inhibitor C1INH (Supplementary Fig. S5), suggesting minimal involvement of the classical pathway in these samples. Measurements of $\mathrm{C} 3$ deposition in a larger cohort of serum samples ( $\mathrm{n}=10$ healthy donors) showed a significant decrease after treatment with EGTA/ $\mathrm{Mg}^{2+}$ (Fig. $\left.1 \mathrm{~g} ; p<0.0001\right)$ in in 5 out of 10 sera, suggesting a role for calcium-sensitive pathways in some of the samples, and predominantly the alternative pathway in other samples. EDTA (a global inhibitor of all complement pathways) inhibited C3 deposition by over $80 \%$ (Fig. 1g; $p<0.0001$ ). Previously we demonstrated the involvement of the lectin pathway in complement activation by SPIO NWs. ${ }^{28}$ Nanoparticles can trigger complement activation via different pathways in different subjects, ${ }^{29}$ but immunoglobulins play a universal role in all tested samples regardless of the activation pathway. Factor $\mathrm{H}(\mathrm{fH})$ is a negative serum regulator of complement convertase that binds to $\mathrm{C} 3 \mathrm{~b}$, promotes cleavage of $\mathrm{C} 3 \mathrm{~b}$ and disassembly of the alternative pathway convertase. Genetic mutations in $\mathrm{fH}$ often lead to deficient binding and inhibition, and hence differences in complement reactivity in general population (termed complotype) ${ }^{30} \mathrm{We}$ measured binding of fH and C3 to SPIO NWs in 12 healthy sera (7 females and 5 males). The amount of deposited C3 directly correlated with the amount of deposited fH (Fig. 1h; $p=0.0003$ ), consistent with the ability of $\mathrm{fH}$ to bind the AP convertase. Addition of $100 \mu \mathrm{g} / \mathrm{mL}$ of purified fH to 3 sera (Fig. 1i, dot blot) and 3 plasma samples (Supplementary Fig. S6, Western blot) resulted in a minimal decrease in C3 opsonisation of SPIO NWs, thereby ruling out the role of $\mathrm{fH}$ in the observed variability in $\mathrm{C} 3$ opsonisation.

Feraheme is a clinically approved monocrystalline ultrasmall SPIO coated with a reduced, negatively charged $10 \mathrm{kDa}$ carboxymethyl dextran (Fig. 2a and Supplementary Table 1). Previously we demonstrated a significant between-subject variability of $\mathrm{C} 3$ binding to Feraheme. ${ }^{18} \mathrm{C} 3$ opsonisation of Feraheme was significantly decreased in 3 protein Adepleted plasma samples (Fig. 2b and Supplementary Fig. S2) and 3 sera (Fig. 2c; $p=0.0029$ ), and reconstitution with polyclonal human IgG increased C3 opsonisation in all plasma (Fig. 2b) and sera (Fig. 2c; $p=0.0315$ ). In a healthy cohort of 12 sera (6 females and 6 males), the correlation between immunoglobulin and C3 binding to Feraheme was significant (Fig. 2d; $p=0.002$ ). C3 opsonisation was not inhibited in 3 plasma samples treated with C1INH (Supplementary Figure S7) and was not significantly inhibited in sera treated with EGTA/ $\mathrm{Mg}^{2+}$ (Fig. 2e; $p=0.99$ ). These data point out that immunoglobulins trigger C3 opsonisation of Feraheme predominantly via the alternative pathway. Since Feraheme is administered as iron supplement to cancer patients, ${ }^{31}$ we tested the effect of IgG on C3 deposition in plasma from metastatic breast cancer patients. Thus, we obtained matched lepirudin-anticoagulated and EDTA-anticoagulated plasma from a cohort of 8 patients with 
breast cancer (description of patients is in Supplementary Table 2). Depletion of immunoglobulins from lepirudin plasma significantly decreased C3 opsonisation of Feraheme (Fig. 2f; $p=0.0016$ ), and reconstitution with purified polyclonal IgG restored or increased complement activation in all samples (Fig. 2f; $p<0.0001$ ). There was little or no $\mathrm{C} 3$ detected on particles incubated in EDTA plasma (Fig. 2f).

Next, we tested the role of immunoglobulins in C3 opsonisation of clinically approved liposomal nanomedicines. PEGylated liposomal doxorubicin (LipoDox ${ }^{\circledR}$, Doxil ${ }^{\circledR}$ ) is a $\sim 100$ nm liposome encapsulating approximately 30,000 doxorubicin molecules (Fig. 3a and Supplementary Table 1) and has been used over 20 years for cancer therapy. ${ }^{32} \mathrm{C} 3$ opsonisation of LipoDox ${ }^{\circledR}$ was significantly reduced in 3 protein A-depleted plasma (Fig. 3b and Supplementary Fig. S2) and 4 sera (Fig. 3c; for dot blot $p<0.0001$ ), and reconstitution with polyclonal human IgG restored C3 opsonisation in both plasma (Fig. 3b) and sera (Fig. $3 c ; p<0.0001)$. In a cohort of 12 healthy sera ( 8 females and 4 males), there was a nonsignificant, but highly suggestive association between levels of immunoglobulin and C3 (Fig. 3d; $p=0.062$ ). C3 opsonisation was not inhibited by C1INH in 3 tested plasma samples (Supplementary Fig. S7), whereas C3 opsonisation was inhibited by $30-60 \%$ by EGTA/ $\mathrm{Mg}^{2+}$ in 5 sera (Fig. 3e; $p<0.0001$ ), suggesting that LipoDox ${ }^{\circledR}$ triggers complement activation in sera via the alternative pathway with some involvement of calcium-dependent pathways. Involvement of the alternative and the lectin pathways in complement activation by PEG was reported before. ${ }^{33}$ In the cohort of lepirudin plasma from 8 breast cancer patients, depletion of immunoglobulins significantly decreased $\mathrm{C} 3$ opsonisation of LipoDox ${ }^{\circledR}$ in all samples (Fig. 3f; $p<0.0001$ ) and C3 deposition was increased or completely restored upon IgG reconstitution in 5 out of 8 samples (Fig. 3f; $p=0.0199$ ). Notably, complete restoration of complement activation in samples 29 and 51 was achieved with a different batch of polyclonal IgG, suggesting that this batch contained IgG clones that could efficiently activate complement.

Onivyde ${ }^{\circledR}$ is a $120 \mathrm{~nm}$ non-PEGylated liposome internally loaded with $~ 70,000$ molecules of irinotecan (Fig. 3g and Supplementary Table 1), and was recently approved for gastrointestinal cancers. ${ }^{34}$ Onivyde ${ }^{\circledR}$ showed significant between-subject variability of C3 opsonisation. ${ }^{18} \mathrm{C} 3$ opsonisation of Onivyde ${ }^{\circledR}$ was decreased in 2 out of 3 protein A-depleted plasma samples (Fig. 3h and Supplementary Fig. S2) and in 3 depleted sera (Fig. 3i; $p=0.0018$ ) and reconstitution with polyclonal human $\mathrm{IgG}$ restored or increased $\mathrm{C} 3$ opsonisation in tested plasma samples (Fig. 3h) and sera (Fig. 3i $p=0.0253$ ). In a cohort of 12 healthy sera (5 females and 7 males), there was a significant association between levels of bound immunoglobulin and C3 (Fig. 3j; $p=0.0003$ ). C1INH did not decrease C3 opsonisation in all the plasma samples (Supplementary Fig. S7), whereas EGTA/Mg ${ }^{2+}$ partially decreased it in 2 out of 5 sera (Fig. $3 \mathrm{k} ; p=0.0264$ ), suggesting that immunoglobulins trigger complement predominantly via the alternative pathway. In the cohort of lepirudin plasma from 8 breast cancer patients, depletion of immunoglobulins significantly decreased C3 opsonisation of Onivyde ${ }^{\circledR}$ in all samples (Fig. 31; $p<0.0001$ ), and $\mathrm{C} 3$ deposition was increased upon $\operatorname{IgG}$ reconstitution in 7 out of 8 samples (Fig. 31; $p<0.0001)$. 
We previously found that $\mathrm{C} 3$ covalently binds to adsorbed serum proteins on the nanoparticle surface. ${ }^{15}$ In order to determine whether $\mathrm{C} 3$ attacks surface-absorbed immunoglobulins, protein coronas formed in 6 healthy sera were eluted from SPIO NWs with $2 \%$ SDS, and analysed on a non-reducing gel (protein-C3 complexes should run as high molecular weight bands). ${ }^{35}$ In most of the sera, the eluted immunoglobulin was localised in a high molecular weight fraction (300-500kDa) that co-localised with C3 (Fig. 4a, upper arrow), consistent with $\mathrm{C} 3-\mathrm{IgG}$ complexes as described previously. ${ }^{36}$ In some samples, there was also presence of free IgG (Fig. 4a, lower arrow). Similar result was obtained using lepirudin plasma samples from 5 healthy donors (Supplementary Fig. S8). The fact that the majority of eluted $\mathrm{C} 3$ did not colocalise with $\mathrm{IgG}$ suggests that $\mathrm{IgG}$ serves as a trigger for $\mathrm{C} 3$ opsonisation, rather than a sole scaffold for $\mathrm{C} 3$ binding. According to quantitative stoichiometric analysis of IgG and $\mathrm{C} 3$ binding in 12 sera (Fig. 4b), there are significantly more $\mathrm{C} 3$ molecules than $\mathrm{IgG}$ molecules per SPIO NW (C3/IgG ratio $51 \pm 17 ; p<0.0001$, two-sided t-test), Feraheme ${ }^{\circledR}$ (C3/IgG ratio $51.7 \pm 25.6 ; p<0.0001$, two-sided t-test); LipoDox ${ }^{\circledR}(\mathrm{C} 3 / \mathrm{IgG}$ ratio $1.9 \pm 0.35 ; p<0.0001$, two-sided t-test $)$ and Onivyde ${ }^{\circledR}(\mathrm{C} 3 / \mathrm{IgG}$ ratio $4.2 \pm 2.1 ; p<0.0001$, two-sided $t$-test). Collectively, the results suggest that few surfacebound immunoglobulin molecules can trigger complement $\mathrm{C} 3$ opsonisation.

\section{Biomolecule corona promotes IgG binding to nanoparticles}

We questioned whether other corona proteins besides immunoglobulin play a role in C3 opsonisation. We incubated SPIO NWs with sera of 6 healthy donors and measured total amount of bound protein. The amount of bound $\mathrm{C} 3$ did not correlate with the amount of non$\mathrm{C} 3$ protein in the coronas (Fig. $5 \mathrm{a}$; Pearson $\mathrm{r}^{2}=0.163$; $p=0.4$ ). Coronas with higher $\mathrm{C} 3$ / particle density also contained higher percentage of C3 (Supplementary Fig. S9). These results clearly demonstrate that total bound protein does not determine the efficiency of C3 opsonisation. At the same time, in the same 6 sera, the amount of $\mathrm{C} 3$ showed correlation with properdin, which is a positive regulator of the alternative pathway convertase ${ }^{37}$ (Supplementary Fig. S10). Shotgun proteomics of protein corona of SPIO NWs in 6 sera (Fig. 5b) and 5 lepirudin plasma samples (Fig. 5c) showed enrichment with apolipoproteins, albumin, complement factors, clotting cascade factors, fibronectin, immunoglobulins, carrier proteins and other regulatory proteins. These proteins have been reported to bind to nanoparticles. ${ }^{38,39,40} \mathrm{C} 1 \mathrm{q}$ was not detected on any corona, thereby excluding possible involvement of the classical pathway in complement activation. However, the corona obtained from sera incubations showed presence of MBL-C and/or MASP-1. To test the role of key corona proteins in complement activation, SPIO NWs were briefly preincubated with fibrinogen, fibronectin, albumin, IgG, ApoB-100, HMWK, HDL, LDL, factor $\mathrm{H}$, and properdin, and then added (without washing step) to sera of healthy donors (Fig. 5d). IgG promoted a 3-fold increase in complement $\mathrm{C} 3$ deposition compared with non-preincubated particles $(p<0.0001)$. Fibronectin induced a minor increase in C3 deposition $(p<0.0001)$, whereas other tested proteins and lipoproteins did not enhance or decrease the $\mathrm{C} 3$ deposition (Fig. 5d).

The hallmark of natural antibodies is their ability to recognise self-epitopes on proteins, especially the denatured species. ${ }^{41}$ We questioned whether protein corona facilitates the binding of IgG to nanoparticle surfaces. Purified human IgG was added to PBS, $50 \mathrm{mg} / \mathrm{mL}$ 
human serum albumin or protein A-depleted sera (3 healthy donors) and SPIO NWs, Feraheme ${ }^{\circledR}$, LipoDox ${ }^{\circledR}$ or Onivyde ${ }^{\circledR}$ were added next. As shown in Figures $5 e$ \& $\mathrm{f}$ and Supplementary Figure S11, in PBS there was minimal binding of IgG to all nanoparticle types, except for LipoDox ${ }^{\circledR}$. Importantly, IgG did not bind to any nanoparticle type in presence of serum albumin, whereas $\mathrm{IgG}$ showed efficient binding in presence of protein corona (Fig. 5E-F).

\section{Conclusions}

In summary, we demonstrated that in multiple sera and plasma samples, natural antibodies play the critical role in complement opsonisation of diagnostic nanoparticles and clinically approved nanomedicines, regardless of the activation pathway. More specifically, antibody binding to nanoparticles was dependent on the biomolecule corona and that the binding of few antibody molecules was sufficient to trigger complement activation. Experiments with depleted plasma samples and sera showed that in some samples the levels of $\mathrm{C} 3$ could not be restored to the original levels upon addition of polyclonal IgG (although sufficient quantities of $\mathrm{C} 3$ were present in such media). Indeed, non-specific deposition of antibodies may not necessarily trigger complement activation through any of the three complement pathways. In the case of the alternative pathway, C3b attack and the convertase assembly may strictly depend on specific antibody-epitope binding, where a few antibodies could trigger the process. Thus, the aforementioned results are likely due to different titer and/or absence of some specific immunoglobulin molecules in the polyclonal preparation and specific glycosylation patterns capable of triggering complement in the context of the absorbed biomolecule corona. In terms of complement activation, this introduces considerable variability due to nanoparticle surface heterogeneity, surface defects and solvation patterns within a particular batch ${ }^{42}$ which in turn may not only control the extent of biomolecule deposition and retention, but also their projected conformation and hence epitope exposure, which becomes rate-limiting factor in triggering alternative pathway activation. Therefore, between-subject variability might be due to subtle conformational differences in repertoire of nanoparticle-bound biomolecules and concomitant presence of a specific immunoglobulin titer against the exposed antigenic epitope.

While we demonstrated the role of $\mathrm{IgG}$ in complement activation by nanomedicines, we did not identify the responsible IgG subclasses and cannot at this point exclude the role of other classes of immunoglobulins, which could play an important role in efficiency of complement activation. ${ }^{58}$ Protein $\mathrm{A}$ is known to deplete serum/plasma from $\mathrm{IgG}_{1}, \mathrm{IgG}_{2}, \mathrm{IgG}_{3}$ and to some extent IgM. ${ }^{43}$ Indeed, binding of naturally occurring IgM antibodies against a component of the pristine surface (e.g., anti-PEG and anti-dextran IgM) ${ }^{44}$ could trigger complement activation through the classical pathway. Among tested cohort of donors and nanoparticles, however, we excluded a major role of the classical pathway in complement activation.

While we excluded a direct and predominant $\mathrm{IgG}$ binding to the pristine surfaces, the epitopes responsible for $\mathrm{IgG}$ docking are not known. However, in the case of liposomes, earlier studies have suggested a role for $\beta$-2-glycoprotein 1 deposition in subsequent antiphospholipid antibody binding and eventual complement activation. ${ }^{45}$ Since a few epitopes 
are apparently responsible for IgG docking, proteomic studies may inadvertently overgeneralise the role of NP protein/glycoprotein/lipoprotein corona in complement activation and immune performance. For instance, mass spectrometry cannot distinguish between nonspecific immunoglobulin deposition and immunoglobulin bound to an antigenic epitope. Furthermore, $\mathrm{IgG}$ deposition on a nanoparticle through its $\mathrm{Fc}$ fragment may even suppress (or prevent) complement activation and delay nanoparticle clearance by macrophages in a manner similar to certain pathogenic microbes. ${ }^{43,}, 46,47$

Our results show that for most of the human subjects and nanoparticles tested, the alternative pathway was the predominant activation pathway. Based on our data and the available literature, we propose the following sequence of nanoparticle-mediated alternative activation by immunoglobulins (Fig. 6). A few immunoglobulin molecules recognise and bind the exposed antigenic epitopes of the protein corona. Nascent $\mathrm{C} 3 \mathrm{~b}$ attacks surface bound immunoglobulin (alternately, the latter may have already been attacked in the fluid phase, thereby bringing $\mathrm{C} 3 \mathrm{~b}$ to the particle surface). ${ }^{36} \mathrm{As}$ a result of the initial $\mathrm{C} 3 \mathrm{~b}$ deposition, few convertases (C3bBbProperdin complexes) assemble on the surface, thereby amplifying $\mathrm{C} 3$ cleavage in the vicinity of nanoparticle surface, resulting in covalent binding of highly reactive $\mathrm{C} 3 \mathrm{~b}$ to reactive epitopes (e.g., amino or hydroxyl moieties) of absorbed plasma proteins (or other surface-associated molecules). ${ }^{15}$ The initial C 3 seed hypothesis is further supported by earlier studies where cell surface-absorbed $\operatorname{IgG}$ was shown to initially accommodate $\mathrm{C} 3 \mathrm{~b}$ molecules and the fact that $\mathrm{IgG}$-bound $\mathrm{C} 3 \mathrm{~b}$ was protected up to 30 -fold against inactivation by fluid-phase complement regulators factors $\mathrm{H}$ and I. ${ }^{48,} 49$

Identification of subsets of patients with enhanced propensity for immune reactions towards nanomedicines is a major task. Immunoglobulin binding can promote recognition by macrophages and modulate anaphylaxis. It would be important to see if natural antibody binding could serve as a broad biomarker of nanoparticle clearance and anaphylactic reactions. Such a biomarker could have a tremendous value in prediction of immune response towards nanomedicines in patients. In addition, developing strategies to block the binding of natural antibodies to biomolecular corona can open new opportunities to improve haemocompatibility and safety of nanomedicines.

\section{Methods}

Materials.

Linear dextran (15-25 kDa molecular weight) and iron salts were purchased from SigmaAldrich (Saint Louis, MO). Purified C3 (A113), Factor H (A137), C3b (A114), iC3b (A115), C1 inhibitor (A140) and Properdin (A139) were purchased from Complement Technology (Tyler, TX). All proteins were aliquoted at $1 \mathrm{mg} / \mathrm{mL}$ and stored in $-80^{\circ} \mathrm{C}$. Every protein was exposed to no more than 2 freeze thaw cycles. Purified human $\operatorname{IgG}$ (009-000-003, lots 137386, 134667, 138240), IgM (009-000-012, lot 132713) and AffiniPure goat anti-human IgM (Fc5 $\mu$ specific; 109-005-129, lot 132466) were purchased from Jackson Immuno Research Laboratories (West Grove, PA). Goat anti-human C3 (55117, lot 07314) was from MP Biomedicals (Solon, OH). Murine monoclonal anti-human C1 (A201, lot 062984) was from Quidel (San Diego, CA). Anti-human factor H (A237, lot 4) and anti-factor P (A239, lot 4a) were from Complement Technology. C1q depleted human 
serum (A509, lot 100698) was from Quidel. Secondary donkey anti-goat IRDye 800CW (926-32214, lot C80207-07) and goat anti-human IRDye 680CW (9266807, lot C7072015) were purchased from Li-COR Biosciences (Lincoln, NE). Purified low-density and highdensity lipoproteins were purchased from Athens Research (Athens, GA). Human serum albumin was obtained from Gemini Bioproducts (Sacramento, CA). Fibronectin was purchased from Upstate Cell Signaling (Lake Placid, NY). Feraheme ${ }^{\circledR}$ (lot 10021802 and 10051302) was generously provided by Dr. Natalie Serkova, Department of Radiology, University of Colorado (UC), Denver, USA. Onivyde ${ }^{\circledR}$ (lot 1501279A), LipoDox ${ }^{\circledR}$ (lot 500592 and 500546) and Herceptin ${ }^{\circledR}$ (lot 569330) were provided as sterile leftovers after administration to patients (free of charge) by the UC Denver Cancer Center Pharmacy. All liposomes were stored in original sterile vials at $4{ }^{\circ} \mathrm{C}$ prior to use. Herceptin ${ }^{\circledR}$ (trastuzumab) was dialysed against PBS and stored in frozen aliquots at $-20^{\circ} \mathrm{C}$. Fibrinogen was purchased from Sigma Aldrich. High molecular weight kininogen was kindly provided by Dr. Keith McCrae (Lerner Research Institute, Cleveland, OH). Protein A Sepharose CL-4B (dry beads) was from Sigma Aldrich. All human studies were conducted in accordance with ethical guidelines. Anonymous human sera and plasma from consented healthy donors (males and females, average age $47 \pm 16$ years) were obtained from the University of Colorado Blood Donation Center using "no anticoagulant" Z vacutainer tubes (BD) for sera, or Multiplate ${ }^{\circledR}$ Hirudin (lepirudin) blood tubes (DiaPharma), respectively. Plasma from consented breast cancer patients were obtained at the University of Colorado Cancer Center using $\mathrm{K}_{2}$ EDTA vacutainer tubes (BD) and lepirudin tubes. The plasma was collected under Colorado Multiple Institutional Review Board-approved protocol 16-0610. Sera were processed as described by us previously ${ }^{18}$ and stored in frozen aliquots at $-80 \mathrm{C}$. Plasma was obtained by centrifugation of $\mathrm{K}_{2}$ EDTA or lepirudin tubes at 5,000 $\mathrm{g}$ for $20 \mathrm{~min}$ at room temperature immediately after the collection and stored in frozen aliquots at $-80 \mathrm{C}$.

\section{SPIO Nanoworm synthesis.}

Large SPIO NWs were synthesized from 15-25kDa dextran, Fe(III) chloride and Fe(II) chloride in a modified Molday precipitation method in ammonia ${ }^{50}$ as described by us previously ${ }^{28}$. The ratio between dextran and iron salts determined the final size of the nanoparticles. ${ }^{28}$ Particles were resuspended in sterile water, filtered through $0.45 \mu \mathrm{m}$ filter and stored at $4^{\circ} \mathrm{C}$. Size (intensity weighted diameter) was determined using Zetasizer Nano ZS (Malvern Instruments Ltd, Malvern, UK). At least 2 batches were used in the study (supplementary Table 1).

\section{Label free mass spectrometry.}

SPIO NWs ( $200 \mu \mathrm{L}, 1 \mathrm{mg} \mathrm{Fe} / \mathrm{mL}$ ) were incubated with 6 sera types or 5 lepirudin plasma samples $\left(600 \mu \mathrm{L}\right.$ each) for $15 \mathrm{~min}$ at $37^{\circ} \mathrm{C}$ in Beckman $1.5 \mathrm{~mL}$ polyallomer tubes (BeckmanCoulter, Bera, CA). Nanoparticles were washed 5 times with $1 \mathrm{~mL}$ PBS using Beckman Optima ultracentrifuge (TLA-100.3 rotor, $450,000 \mathrm{~g}, 8 \mathrm{~min}, 4^{\circ} \mathrm{C}$ ). The proteins were eluted from nanoparticles by incubation in $2 \%$ SDS in PBS for $1 \mathrm{~h}$ at room temperature and additional ultracentrifugation. Nanoparticles were pelleted as described above, and the protein concentration in the supernatant was measured using BCA Protein Assay (Thermo Fisher). Sample was processed at the Proteomics and Metabolomics core facility at the Skaggs School of Pharmacy, University of Colorado using previously described filter-aided 
sample purification method. ${ }^{51}$ The sample was separated with a C-18 reverse phase nano LC column $(100 \mu \mathrm{m} \times 150 \mathrm{~mm}, 3.0 \mu \mathrm{m}, 200 \mathrm{~A}$; ProntoSil C18AQ by Nano LCMS Solutions (Rancho Cordova, CA)). The sample was loaded onto a trap column of the same packing material for 5 minutes at $10 \mu \mathrm{L} / \mathrm{min}$ before the elution gradient. The flow rate was $800 \mathrm{~nL} /$ min. One microliter of sample was injected. The MS data was acquired in triplicates using Bruker Impact HD Q-TOF mass spectrometer in a the nano-booster mode with the following criteria: mass range of $150-2200 \mathrm{~m} / \mathrm{z}$, scan rate of $2.0 \mathrm{~Hz}$, precursor cycle time of $3.0 \mathrm{sec}$, absolute threshold of 500 counts, $0 \%$ relative threshold, exclude after 1 spectra and release after $2 \mathrm{~min}$, and reconsider precursor if the current intensity: previous intensity is 3.0. The MS/MS spectra were run against the Swiss-Prot human database with ProteinScape 4.0 (Bruker) using Mascot software. Trypsin cleavage specificity was set with a maximum of two missed cleavages allowed and variable cysteinyl carbamidomethylation, deamidation (NQ), and oxidised methionine modifications were allowed. Peptide tolerance was set to $10.0 \mathrm{ppm}$ and a $\mathrm{ms} / \mathrm{ms}$ tolerance to $0.5 \mathrm{Da}$. Peptides must be at least 5 amino acids long, and proteins were accepted with a Mascot score of $>40$, and peptides were accepted with a Mascot score $>20$.

\section{Assay of proteins bound to nanoparticles.}

A solution of PBS with $1 \mathrm{mg} / \mathrm{mL}$ (Fe or drug) of SPIO NWs, Feraheme ${ }^{\circledR}$, LipoDox ${ }^{\circledR}$ or Onivyde ${ }^{\circledR}$ was incubated at a 1:3 volume ratio with serum or plasma for $30 \mathrm{~min}$ in a $37^{\circ} \mathrm{C}$ water bath. Following incubation, samples were washed 5 times with PBS at $4^{\circ} \mathrm{C}$ using ultracentrifuge as described above for proteomic studies. To determine the amount of specific proteins bound to nanoparticles, a quantitative immuno dot blot assay was used as described. ${ }^{15,18,24,28}$. Briefly, the pellets were resuspended in PBS, and $2 \mu \mathrm{L}$ of each sample was pipetted in triplicates onto a nitrocellulose membrane $(0.45 \mu \mathrm{m}$ pore, Bio-Rad $)$.

Standard 2-fold dilutions of purified protein standards were applied to the same membrane ( $2 \mu \mathrm{L}$ dots in triplicate). Calibrated $2 \mu \mathrm{L}$ volume Eppendorf pipette was used for dot application. The membranes were blocked with a blocking buffer of 5\% w/w nonfat dry milk in PBS-T (1x PBS and 0.1\% v/v Tween-20) for $1 \mathrm{~h}$ at room temperature, probed with the primary antibody for $1 \mathrm{~h}$ at room temperature, followed by washes (3x) with PBS-T. Lastly, the membranes were probed with corresponding secondary antibody labelled with IRDye 680 or IRDye 800 (1:20,000 in blocking buffer) for $1 \mathrm{~h}$ at room temperature and washed 3 times with PBS-T. The membranes were scanned using the Odyssey infrared imager (LiCOR Biosciences, Lincoln, NE) at either $700 \mathrm{~nm}$ or $800 \mathrm{~nm}$ depending on the label of secondary antibodies. For dot blot quantification, the background of 16-bit grayscale images was subtracted and integrated densities of the dots were measured with ImageJ software. The number of protein molecules per dot was determined from a standard curve of a protein dotted on the same membrane. Number of protein molecules per mg nanoparticle was calculated by dividing the number of molecules/dot by the amount of nanoparticles (mg Fe or mg drug) applied per dot. The previously calculated molar concentrations of nanoparticles and liposomes per mg Fe or drug ${ }^{18}$ were used.

For non-reducing Western blot, proteins were eluted from washed nanoparticle pellet with $2 \%$ SDS in PBS for $1 \mathrm{~h}$ at room temperature, the particles were pelleted with ultracentrifuge, the supernatant was mixed with Bio-Rad sample buffer without beta-mercaptoethanol and 
separated on a 4-20\% Tris-Glycine SDS-PAGE. For reducing Western blot, nanoparticles after washing were resuspended in reducing sample buffer, boiled for $2 \mathrm{~min}$ at $95^{\circ} \mathrm{C}$ and separated on a 4-20\% Tris-Glycine SDS-PAGE. The proteins were transferred to nitrocellulose membrane, and processed as described for dot blot assay above. For detection of $\mathrm{C} 3$ and $\mathrm{IgG}$ on the same membrane, first C3 was detected with IRDye800CW-labelled antibody, then the membrane was washed and IgG was detected with IRDye680-labelled antibody. Both dyes were detected by scanning membrane at 700 and $800 \mathrm{~nm}$ with Li-COR Odyssey.

\section{Pre-incubation of proteins with SPIO NWs.}

Purified protein solutions in PBS or in the vendors' buffers (kininogen $1 \mathrm{mg} / \mathrm{mL}$, fibronectin $1 \mathrm{mg} / \mathrm{mL}$, fibrinogen $1 \mathrm{mg} / \mathrm{mL}$, factor $\mathrm{H} 1 \mathrm{mg} / \mathrm{mL}$, properdin $1 \mathrm{mg} / \mathrm{mL}$, human serum albumin $50 \mathrm{mg} / \mathrm{mL}$, Apo-B100 $1.9 \mathrm{mg} / \mathrm{mL}, \mathrm{IgG} 11.6 \mathrm{mg} / \mathrm{mL}$, HDL $1 \mathrm{mg} / \mathrm{mL}$ and LDL 1 $\mathrm{mg} / \mathrm{mL}$ ), or control PBS or corresponding proteins' buffer in the same volume were preincubated with SPIO NWs $(1 \mathrm{mg} / \mathrm{mL}$ in PBS) at a 1:1 v/v ratio for $15 \mathrm{~min}$ at room temperature. Following pre-incubation, serum was added to nanoparticles at a 3:2 volume ratio, the nanoparticles were incubated, washed and assayed for bound $\mathrm{C} 3$ as described for dot blot assay. The experiments were performed in 3 different sera for each tested protein.

\section{Immunoglobulin depletion and reconstitution.}

To deplete serum or plasma of immunoglobulin (predominantly $\operatorname{IgG}$ ), $0.05 \mathrm{~g}$ of dry protein A sepharose was added to a $1.7 \mathrm{~mL}$ Eppendorf tube. Next, $500 \mu \mathrm{L}$ of PBS was added to each tube and beads were allowed to swell for $30 \mathrm{~min}$ room temperature. At the end of the swelling period, tubes were centrifuged at 3,000 $\mathrm{g}$ for $1 \mathrm{~min}$ and supernatant was removed from the slurry with a capillary gel-loading tip until the beads became almost dry (minimal carryover volume) and placed on ice. $200 \mu \mathrm{L}$ of freshly thawed cooled serum or lepirudin plasma were added and gently agitated on a thermal mixer for $30 \mathrm{~min}$ at $4{ }^{\circ} \mathrm{C}$ in order to limit complement activation. Following agitation, samples were centrifuged for $1 \mathrm{~min}$ at $3,000 \mathrm{~g}$ at $4^{\circ} \mathrm{C}$. Supernatant was carefully removed with a capillary gel loading tip (without aspirating the slurry) and stored in aliquots at $-80^{\circ} \mathrm{C}$. For reconstitution, human $\operatorname{IgG}, \operatorname{IgM}$ or trastuzumab (stock concentrations between $11.6 \mathrm{mg} / \mathrm{mL}$ and $14 \mathrm{mg} / \mathrm{mL}$ )) or PBS (control) were added to depleted sera or plasma in a 1:3 ratio and incubated at room temperature for $15 \mathrm{~min}$, before addition of nanoparticles. Adult serum IgG levels are $767-1,590 \mathrm{mg} / \mathrm{dL}$ or $7.67-15.9 \mathrm{mg} / \mathrm{mL}$. IgM serum levels are $37-286 \mathrm{mg} / \mathrm{dL}$, or $0.37-2.86 \mathrm{mg} / \mathrm{mL}$. Given the limitation of stock concentration of $\mathrm{IgG}$ and $\operatorname{IgM}$ (between $11.6 \mathrm{mg} / \mathrm{mL}$ and $14 \mathrm{mg} / \mathrm{mL}$ ), the final immunoglobulin levels were $2.9-3.5 \mathrm{mg} / \mathrm{mL}$, which is lower than native $\operatorname{IgG}$ but similar to native IgM levels. Three different batches of purified IgG and one batch of purified IgM and one batch of trastuzumab were used for reconstitution experiments. The particles were incubated, washed and analysed with dot blot or Western blot as described above.

\section{Complement inhibition studies.}

To distinguish between pathways of complement activation, the inhibitor of $\mathrm{Ca}^{2+}$-sensitive pathways EGTA/ $\mathrm{Mg}^{2+}(10 \mathrm{mM}$ EDTA and $10 \mathrm{mM} \mathrm{MgCl}$ final concentration), the inhibitor of both the alternative pathway and calcium-sensitive pathways EDTA $(10 \mathrm{mM}$ final 
concentration), the inhibitor of classical pathway $\mathrm{C} 1 \mathrm{INH}(2.2 \mu \mathrm{M}$ final concentration) or $1 \mathrm{x}$ PBS (control) were added to sera or plasma samples at room temperature $30 \mathrm{~min}$ prior to the experiment. Purified factor $\mathrm{H}$ was added to sera at 1:10 ratio for a final concentration of 100 $\mu \mathrm{g} / \mathrm{mL}$. Nanoparticles ( $1 \mathrm{mg} / \mathrm{mL}$ Fe or drug) were then added to sera or plasma (1:3 nanoparticle:serum volume ratio) and incubated at $37^{\circ} \mathrm{C}$ for $30 \mathrm{~min}$. Samples were processed in a dot blot protocol listed above.

\section{Statistical Analyses.}

Statistical analyses were done using R statistical software (version 3.4.3) and RStudio (version 1.1.383), or Prism 7.0 (version 7.0a, GraphPad, Dan Diego, CA). Graphics were created with R (heatmap) or with Prism 7.0. Three technical replicates per sample were measured for each outcome. A linear mixed model that accounted for repeated measures within a subject was used for $\operatorname{IgG}$ versus $\mathrm{C} 3$ and $\mathrm{IgG}$ versus Factor $\mathrm{H}$ analyses and executed using the lme4 package (version 1.1-15) in R. Statistical significance for pairwise post hoc testings of the marginal means from a linear mixed model was calculated using two-sided ttest and a Tukey multiple testing correction in the emmeans (version 1.1) package in R. For Fig. 5d, statistical significance for pairwise post hoc testing of the marginal means from a linear mixed model was calculated using two-sided t-test and a Dunnett multiple testing correction.

\section{Data availability.}

The mass spectrometry proteomics data have been deposited to the ProteomeXchange Consortium via the PRIDE partner repository with the dataset identifier PXD011781. The raw data that support the graphs $1 \mathrm{c}, \mathrm{d}, \mathrm{e}, \mathrm{g}, \mathrm{h}, \mathrm{i} ; 2 \mathrm{c}, \mathrm{d}, \mathrm{e}, \mathrm{f} ; 3 \mathrm{c}, \mathrm{d}, \mathrm{e}, \mathrm{f}, \mathrm{i}, \mathrm{j}, \mathrm{k}, \mathrm{l}$; and 5d, are available in extended Supplementary Information. Any additional data and data analysis scripts for R are available from L.S. upon request.

\section{Supplementary Material}

Refer to Web version on PubMed Central for supplementary material.

\section{Acknowledgements}

The study was funded by the National Institutes of Health grants EB022040, CA194058, CA174560 to D.S. and Diagnologix, LLC (San Diego, CA) to D.S. FC was supported by the International Postdoctoral Exchange Fellowship Program (2013) from China Postdoctoral Council. S.M.M. acknowledges support by International Science and Technology Cooperation of Guangdong Province (reference 2015A050502002), and Guangzhou City (reference 2016201604030050) with RiboBio Co, Ltd., China. Authors would like to thank Nirmal K. Banda and V. Michael Holers for their valuable suggestions during this work.

\section{References}

1. D'Mello SR, et al. The evolving landscape of drug products containing nanomaterials in the united states. Nat. Nanotech. 12, 523-529 (2017).

2. Boraschi D, et al. Nanoparticles and innate immunity: New perspectives on host defence. Semin. Immunol. 34, 33-51 (2017). [PubMed: 28869063]

3. Monopoli MP, et al. Physical-chemical aspects of protein corona: Relevance to in vitro and in vivo biological impacts of nanoparticles. J. Am. Chem. Soc 133, 2525-2534 (2011). [PubMed: 21288025] 
4. Cedervall T, et al. Understanding the nanoparticle-protein corona using methods to quantify exchange rates and affinities of proteins for nanoparticles. Proc. Natl. Acad. Sci. U. S. A 104, 20502055 (2007). [PubMed: 17267609]

5. Karmali PP, Simberg D Interactions of nanoparticles with plasma proteins: Implication on clearance and toxicity of drug delivery systems. Expert Opin Drug Deliv 8, 343-357 (2011). [PubMed: 21291354]

6. Salvati A, et al. Transferrin-functionalized nanoparticles lose their targeting capabilities when a biomolecule corona adsorbs on the surface. Nat. Nanotech. 8, 137-143 (2013).

7. Mortimer GM, et al. Cryptic epitopes of albumin determine mononuclear phagocyte system clearance of nanomaterials. ACS Nano 8, 3357-3366 (2014). [PubMed: 24617595]

8. Shannahan JH, et al. Formation of a protein corona on silver nanoparticles mediates cellular toxicity via scavenger receptors. Toxicol. Sci. 143, 136-146 (2015). [PubMed: 25326241]

9. Deng ZJ, et al. Nanoparticle-induced unfolding of fibrinogen promotes mac-1 receptor activation and inflammation. Nat. Nanotech. 6, 39-44 (2011).

10. Ricklin D, Hajishengallis G, Yang K, Lambris JD Complement: A key system for immune surveillance and homeostasis. Nat. Immunol. 11, 785-797 (2010). [PubMed: 20720586]

11. Wibroe PP, et al. Bypassing adverse injection reactions to nanoparticles through shape modification and attachment to erythrocytes. Nat. Nanotech. 12, 589-594 (2017).

12. Anchordoquy TJ, Simberg D Watching the gorilla and questioning delivery dogma. J. Control. Release 262, 87-90 (2017). [PubMed: 28713040]

13. Moghimi SM Nanomedicine safety in preclinical and clinical development: Focus on idiosyncratic injection/infusion reactions. Drug Discov. Today 23, 1034-1042 (2018). [PubMed: 29146517]

14. Chanan-Khan A, et al. Complement activation following first exposure to pegylated liposomal doxorubicin (doxil): Possible role in hypersensitivity reactions. Ann. Oncol 14, 1430-1437 (2003). [PubMed: 12954584]

15. Chen $\mathrm{F}$, et al. Complement proteins bind to nanoparticle protein corona and undergo dynamic exchange in vivo. Nat. Nanotech. 12, 387-393 (2017).

16. Nahrendorf M, et al. Hybrid PET-optical imaging using targeted probes. Proc. Natl. Acad. Sci. U. S. A. 107, 7910-7915 (2010). [PubMed: 20385821]

17. Gazeau F, Levy M, Wilhelm C Optimizing magnetic nanoparticle design for nanothermotherapy. Nanomedicine (Lond) 3, 831-844 (2008). [PubMed: 19025457]

18. Benasutti $\mathrm{H}$, et al. Variability of complement response toward preclinical and clinical nanocarriers in the general population. Bioconjug. Chem 28, 2747-2755 (2017). [PubMed: 29090582]

19. Schenkein HA, Ruddy S The role of immunoglobulins in alternative pathway activation by zymosan. II. The effect of IgG on the kinetics of the alternative pathway. J. Immunol 126, 11-15 (1981). [PubMed: 6905857]

20. Schenkein HA, Ruddy S The role of immunoglobulins in alternative complement pathway activation by zymosan. I. Human igg with specificity for zymosan enhances alternative pathway activation by zymosan. J. Immunol. 126, 7-10 (1981). [PubMed: 6778918]

21. Russell MW, Mansa B Complement-fixing properties of human IgA antibodies. Alternative pathway complement activation by plastic-bound, but not specific antigen-bound, IgA. Scand. J. Immunol. 30, 175-183 (1989). [PubMed: 2762767]

22. Andersson J, Ekdahl KN, Lambris JD, Nilsson B Binding of C3 fragments on top of adsorbed plasma proteins during complement activation on a model biomaterial surface. Biomaterials 26 , 1477-1485 (2005). [PubMed: 15522749]

23. Wang G, et al. High-relaxivity superparamagnetic iron oxide nanoworms with decreased immune recognition and long-circulating properties. ACS Nano 8, 12437-12449 (2014). [PubMed: 25419856]

24. Wang G, et al. In vitro and in vivo differences in murine third complement component (C3) opsonization and macrophage/leukocyte responses to antibody-functionalized iron oxide nanoworms. Front. Immunol. 8, 151 (2017). [PubMed: 28239384]

25. Duncan AR, Winter G The binding site for C1q on IgG. Nature 332, 738-740 (1988). [PubMed: 3258649] 
26. Banda NK, et al. Initiation of the alternative pathway of murine complement by immune complexes is dependent on n-glycans in igg antibodies. Arthritis Rheum. 58, 3081-3089 (2008). [PubMed: 18821684]

27. Malhotra R, et al. Glycosylation changes of igg associated with rheumatoid arthritis can activate complement via the mannose-binding protein. Nat. Med. 1, 237-243 (1995). [PubMed: 7585040]

28. Wang G, et al. Activation of human complement system by dextran-coated iron oxide nanoparticles is not affected by dextran/fe ratio, hydroxyl modifications, and crosslinking. Front. Immunol. 7, 418 (2016). [PubMed: 27777575]

29. Quach QH, Kah JC Non-specific adsorption of complement proteins affects complement activation pathways of gold nanomaterials. Nanotoxicology 11, 382-394 (2017). [PubMed: 28287003]

30. Harris CL, Heurich M, Rodriguez de Cordoba S, Morgan BP The complotype: Dictating risk for inflammation and infection. Trends Immunol. 33, 513-521 (2012). [PubMed: 22749446]

31. Macdougall IC Iron supplementation in nephrology and oncology: What do we have in common? Oncologist 16 Suppl 3, 25-34 (2011).

32. Gabizon A, Martin F Polyethylene glycol-coated (pegylated) liposomal doxorubicin. Rationale for use in solid tumours. Drugs 54 Suppl 4, 15-21 (1997).

33. Hamad I, Hunter AC, Szebeni J, Moghimi SM Poly(ethylene glycol)s generate complement activation products in human serum through increased alternative pathway turnover and a MASP-2-dependent process. Mol. Immunol. 46, 225-232 (2008). [PubMed: 18849076]

34. Kang MH, et al. Activity of mm-398, nanoliposomal irinotecan (nal-iri), in ewing's family tumor xenografts is associated with high exposure of tumor to drug and high slfn11 expression. Clin. Cancer. Res. 21, 1139-1150 (2015). [PubMed: 25733708]

35. Ramadass M, Ghebrehiwet B, Smith RJ, Kew RR Generation of multiple fluid-phase C3b:Plasma protein complexes during complement activation: Possible implications in c3 glomerulopathies. J. Immunol. 192, 1220-1230 (2014). [PubMed: 24367026]

36. Gadd KJ, Reid KB The binding of complement component C3 to antibody-antigen aggregates after activation of the alternative pathway in human serum. Biochem. J. 195, 471-480 (1981). [PubMed: 7316962]

37. Pauly D, et al. A novel antibody against human properdin inhibits the alternative complement system and specifically detects properdin from blood samples. PLoS One 9, e96371 (2014). [PubMed: 24797388]

38. Sakulkhu U, et al. Protein corona composition of superparamagnetic iron oxide nanoparticles with various physico-chemical properties and coatings. Sci. Rep. 4, 5020 (2014). [PubMed: 24846348]

39. Tenzer $S$, et al. Rapid formation of plasma protein corona critically affects nanoparticle pathophysiology. Nat. Nanotech. 8, 772-781 (2013).

40. Walkey CD, et al. Protein corona fingerprinting predicts the cellular interaction of gold and silver nanoparticles. ACS Nano 8, 2439-2455 (2014). [PubMed: 24517450]

41. Holodick NE, Rodriguez-Zhurbenko N, Hernandez AM Defining natural antibodies. Front. Immunol. 8, 872 (2017). [PubMed: 28798747]

42. Moghimi SM, Simberg D Complement activation turnover on surfaces of nanoparticles. Nano Today 15, 8-10 (2017). [PubMed: 29399037]

43. Sulica A, et al. Effect of protein a of staphylococcus aureus on the binding of monomeric and polymeric igg to fc receptor-bearing cells. Immunology 38, 173-179 (1979). [PubMed: 511216]

44. Le Y, Toyofuku WM, Scott MD Immunogenicity of murine mPEG-red blood cells and the risk of anti-peg antibodies in human blood donors. Exp. Hematol. 47, 36-47 e32 (2017). [PubMed: 27864153]

45. Jones JV, James H, Tan MH, Mansour M Antiphospholipid antibodies require beta 2-glycoprotein I (apolipoprotein H) as cofactor. J. Rheumatol. 19, 1397-1402 (1992). [PubMed: 1433008]

46. Laky M, Sjoquist J, Moraru I, Ghetie V Mutual inhibition of the binding of Clq and protein a to rabbit IgG immune complexes. Mol. Immunol. 22, 1297-1302 (1985). [PubMed: 3878459]

47. Zhang L, et al. A second igg-binding protein in staphylococcus aureus. Microbiology 144, 985991 (1998). [PubMed: 9579072] 
48. Fries LF, Gaither TA, Hammer CH, Frank MM C3b covalently bound to igg demonstrates a reduced rate of inactivation by factors H and I. J. Exp. Med. 160, 1640-1655 (1984). [PubMed: 6239898]

49. Venkatesh YP, Minich TM, Law SK, Levine RP Natural release of covalently bound C3b from cell surfaces and the study of this phenomenon in the fluid-phase system. J. Immunol. 132, 1435-1439 (1984). [PubMed: 6693771]

50. Molday RS, MacKenzie D Immunospecific ferromagnetic iron-dextran reagents for the labeling and magnetic separation of cells. J. Immunol. Methods 52, 353-367 (1982). [PubMed: 7130710]

51. Wisniewski JR, Zougman A, Nagaraj N, Mann M Universal sample preparation method for proteome analysis. Nat. Methods 6, 359-362 (2009). [PubMed: 19377485] 
a

b

C
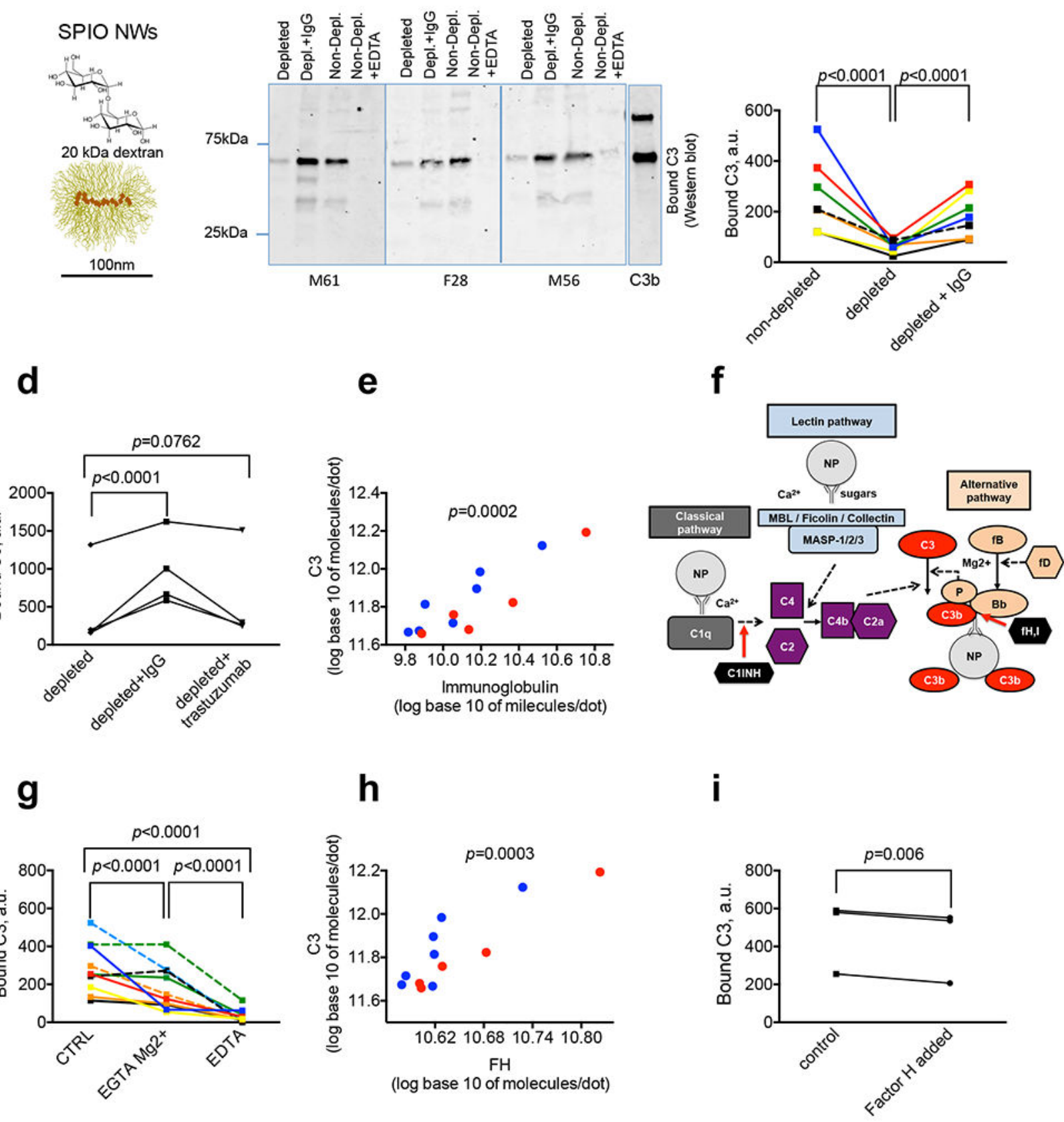

Fig. 1. Role of immunoglobulins in efficiency of C3 deposition on SPIO NWs:

a) schematic representation of SPIO NWs. Yellow indicates dextran chains and brown represents iron oxide nanocrystals; b) immunoglobulin depletion from plasma samples with protein $\mathrm{A}$ beads decreases complement $\mathrm{C} 3$ deposition and addition of polyclonal human $\mathrm{IgG}$ restores $\mathrm{C} 3$ deposition. The absence of a' chain $(110 \mathrm{kDa})$ on SPIO NWs is due to cleavage by factor I into $\mathrm{iC} 3 \mathrm{~b} / \mathrm{C} 3 \mathrm{dg} / \mathrm{C} 3 \mathrm{c}$ fragments. These experiments were repeated independently 3 times in 3 different plasma samples with similar results; c) depletion experiments as in panel (b) were performed in sera of healthy donors ( $\mathrm{n}=7$ subjects) and $\mathrm{C} 3$ was analysed in a 
dot blot assay. Each dot represents the mean of 3 technical replicates per sample; d) addition of trastuzumab (monoclonal human IgG) to depleted sera ( $\mathrm{n}=4$ subjects) did not restore $\mathrm{C} 3$ deposition. Lines connecting points indicate measures from the same subject. Each dot represents the mean of 3 technical replicates per sample; e) association between levels of immunoglobulin and C 3 on SPIO NWs in a cohort of healthy donors ( $\mathrm{n}=12$ subjects) measured with dot blot assay. Red points indicate male samples and blue points indicate female samples. Each point represents the mean of 3 technical replicates; f) schematic diagram showing how nanoparticle-bound immunoglobulins may trigger complement activation. These include the classical pathway via $\mathrm{C} 1 \mathrm{q}$ binding to the $\mathrm{Fc}$ portion of surfacebound antibodies, the lectin pathway via MBL/MASP-2 binding to glycosylated regions of antibodies and the alternative pathway, via deposition of antibody-bound C3. Natural inhibitors of complement are shown as black objects with red arrows; $\mathbf{g}$ ) nanoparticles were incubated in sera supplemented with EGTA/ $\mathrm{Mg}^{2+}$ (inhibitor of the classical and lectin pathways) and EDTA (inhibitor of all pathways) and C3 deposition was measured with dot blot. In panels (c) \& (g) same colour refers to the same individual ( $\mathrm{n}=10$ subjects). Each dot represents the mean of 3 technical replicates per sample; $\mathbf{h}$ ) Samples [as in panel (e)] were probed for Factor $\mathrm{H}(\mathrm{fH})$ binding. $\mathrm{FH}$ is a serum inhibitor of convertase that binds to $\mathrm{C} 3 \mathrm{~b}$. There was a positive association between levels of bound inhibitor and C3 in sera of healthy donors ( $\mathrm{n}=12$ subjects). Red dots indicate male samples and blue dots indicate female samples. Each dot represents the mean of 3 technical replicates per sample; i) Addition of purified $\mathrm{fH}(100 \mu \mathrm{g} / \mathrm{mL})$ to sera with high and intermediate complement activation ( $\mathrm{n}=3$ subjects) only minimally decreased $\mathrm{C} 3$ deposition as measured with dot blot, suggesting that $\mathrm{fH}$ deficiency is not responsible for high level of $\mathrm{C} 3$ deposition. Each dot represents the mean of 3 technical replicates per sample. In all experiments, lines connecting points indicate measures from the same subject. Colours designate different individuals. Statistical analysis is explained in Methods. 
a b
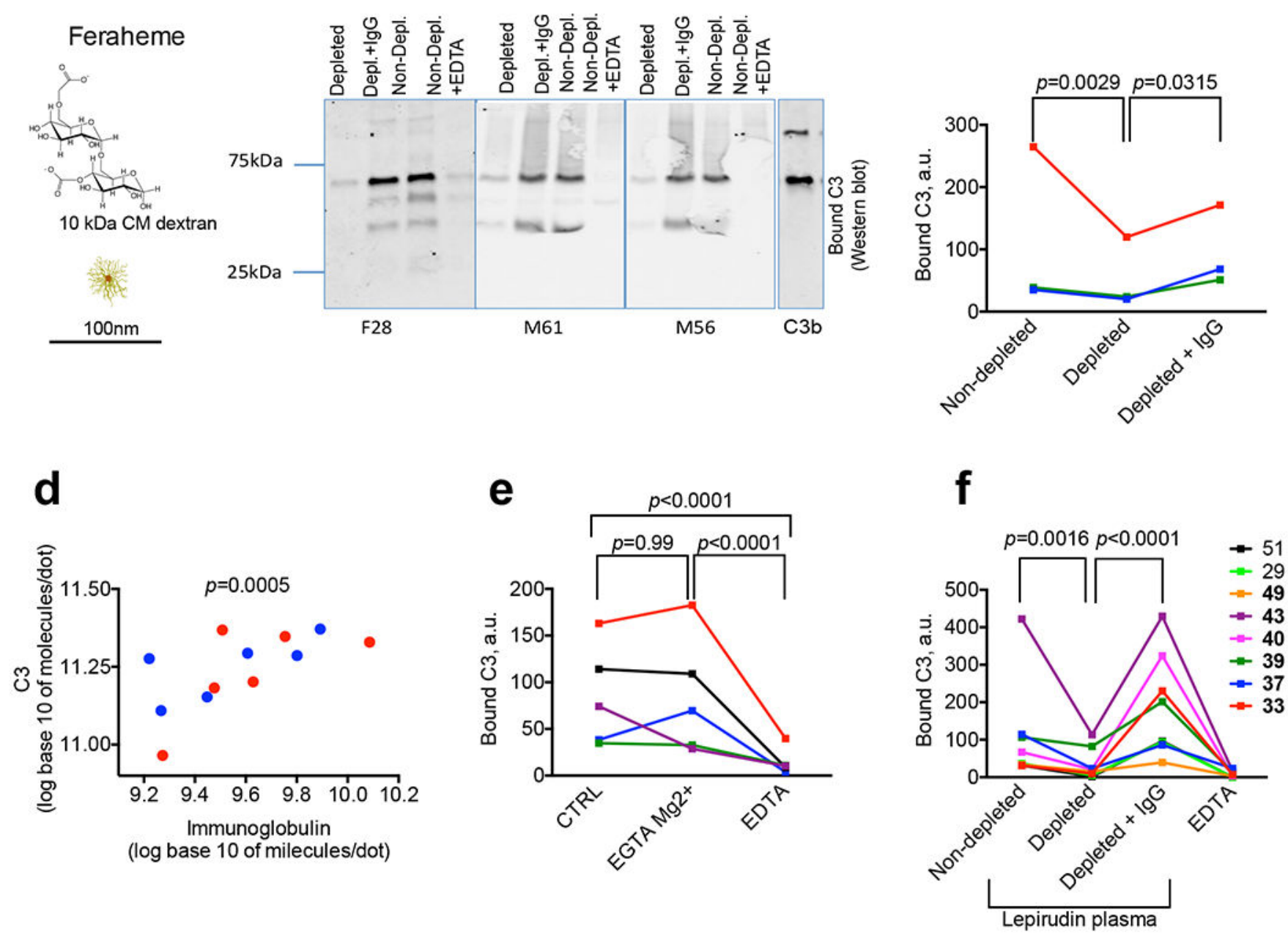

Fig. 2. Role of immunoglobulins in efficiency of $\mathrm{C} 3$ deposition on clinically approved SPIO Feraheme $^{\circledR}$ :

a) schematic representation of Feraheme ${ }^{\circledR}$ structure; b) effect of immunoglobulin depletion and reconstitution in plasma of healthy donors. These experiments were repeated independently 3 times in 3 different plasma samples with similar results; c) effect of immunoglobulin depletion in sera of healthy donors ( $n=3$ subjects) measured with dot blot. Each dot represents the mean of 3 technical replicates per sample; d) correlation between levels of immunoglobulins and C3 bound to Feraheme ${ }^{\circledR}$ in healthy sera ( $n=12$ subjects). Red points indicate male samples and blue points indicate female samples. Each point is the mean of 3 experimental replicates and 3 technical replicates per sample; e) Feraheme ${ }^{\circledR}$ was incubated in sera with EGTA/ $\mathrm{Mg}^{2+}$ or EDTA ( $\mathrm{n}=5$ subjects). In panels (c) and (e), same colour refers to the same individual. Each dot represents the mean of 3 technical replicates per sample; f) immunoglobulin depletion and reconstitution in lepirudin-anticoagulated plasma from breast cancer patients ( $n=8$ subjects). Each dot represents the mean of 3 technical replicates per sample. EDTA-anticoagulated plasma was from the same patient. In 
all graphs, lines connecting points indicate measures from the same subject. Colours designate different individuals. Statistical analysis is explained in Methods. 

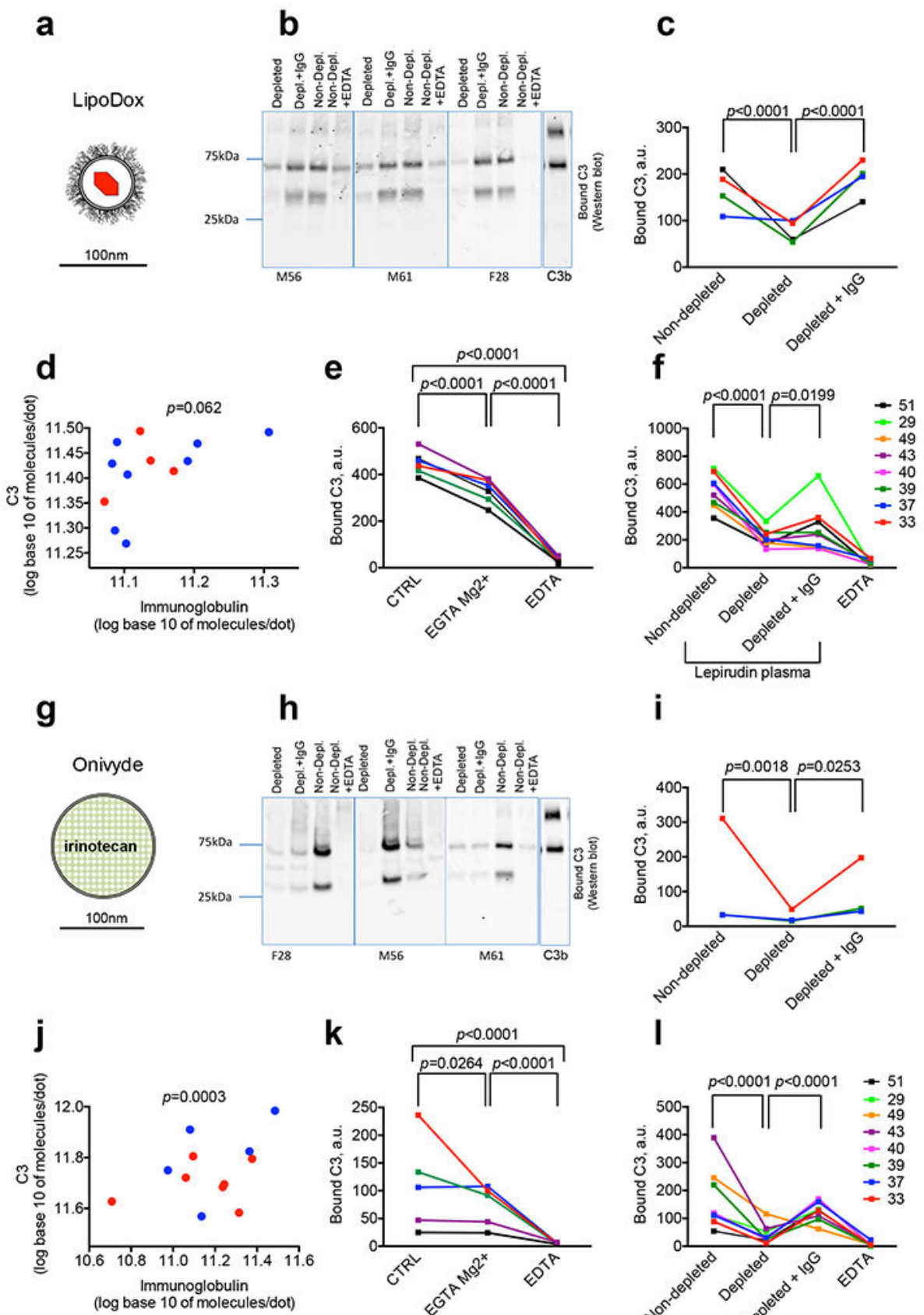

\section{i}
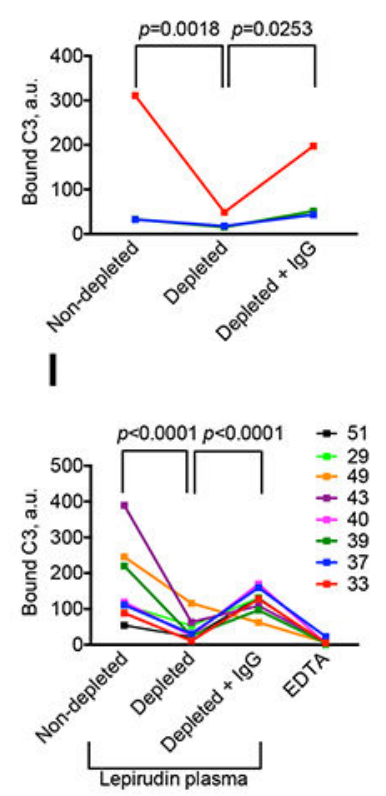

Fig. 3. Role of immunoglobulins in efficiency of $\mathrm{C} 3$ deposition on clinically approved liposomes: a) schematic representation of LipoDox ${ }^{\circledR}$ (a generic version of Doxil ${ }^{\circledR}$, a regulatory approved liposomal doxorubicin); b) effect of immunoglobulin depletion and reconstitution in plasma samples of healthy donors. These experiments were repeated independently 3 times in 3 different plasma samples with similar results; c) effect of immunoglobulin depletion and reconstitution in healthy sera ( $\mathrm{n}=4$ subjects), measured with dot blot. Each dot represents the mean of 3 technical replicates per sample; d) correlation between levels of immunoglobulin and $\mathrm{C} 3$ bound to LipoDox ${ }^{\circledR}$ in healthy sera ( $\mathrm{n}=12$ subjects). Red points 
indicate male samples and blue points indicate female samples. Each point is the mean of 3 experimental and 3 technical replicates per sample; e) nanoparticles were incubated in serum with EGTA/Mg ${ }^{2+}$ or EDTA ( $\mathrm{n}=5$ subjects). In panels (c) and (e) same colour refers to the same individual. Each dot represents the mean of 3 technical replicates per sample; f) immunoglobulin depletion and reconstitution in lepirudin-anticoagulated plasma from breast cancer patients ( $\mathrm{n}=8$ subjects). Each dot represents the mean of 3 technical replicates per sample. EDTA-anticoagulated plasma was from the same patient; $\mathbf{g}$ ) schematic representation of Onivyde ${ }^{\circledR}$, a clinically approved liposomal irinotecan; h) effect of immunoglobulin depletion and reconstitution in plasma of healthy donors. These experiments were repeated independently 3 times in 3 different plasma samples with similar results; i) effect of immunoglobulin depletion and reconstitution in healthy sera ( $\mathrm{n}=3$ subjects). Each dot represents the mean of 3 technical replicates per sample; $\mathbf{j}$ ) association between levels of immunoglobulin and C3 bound to Onivyde ${ }^{\circledR}$ in healthy sera $(n=12$ subjects). Red points indicate male samples and blue points indicate female samples. Each point is the mean of 3 experimental and 3 technical replicates per sample; $\mathbf{k}$ ) effect of EGTA/ $\mathrm{Mg}^{2+}$ or EDTA on $\mathrm{C} 3$ deposition in healthy sera ( $\mathrm{n}=5$ subjects). In panels (i) and (k) the same colour refers to the same individual. Each dot represents the mean of 3 technical replicates per sample; I) IgG depletion and reconstitution in lepirudin-anticoagulated plasma from breast cancer patients ( $\mathrm{n}=8$ subjects). Each dot represents the mean of 3 technical replicates per sample. EDTA-anticoagulated plasma was from the same patient. In all graphs, lines connecting points indicate measures from the same subject. Colours designate different individuals. Statistical analysis is explained in Methods 

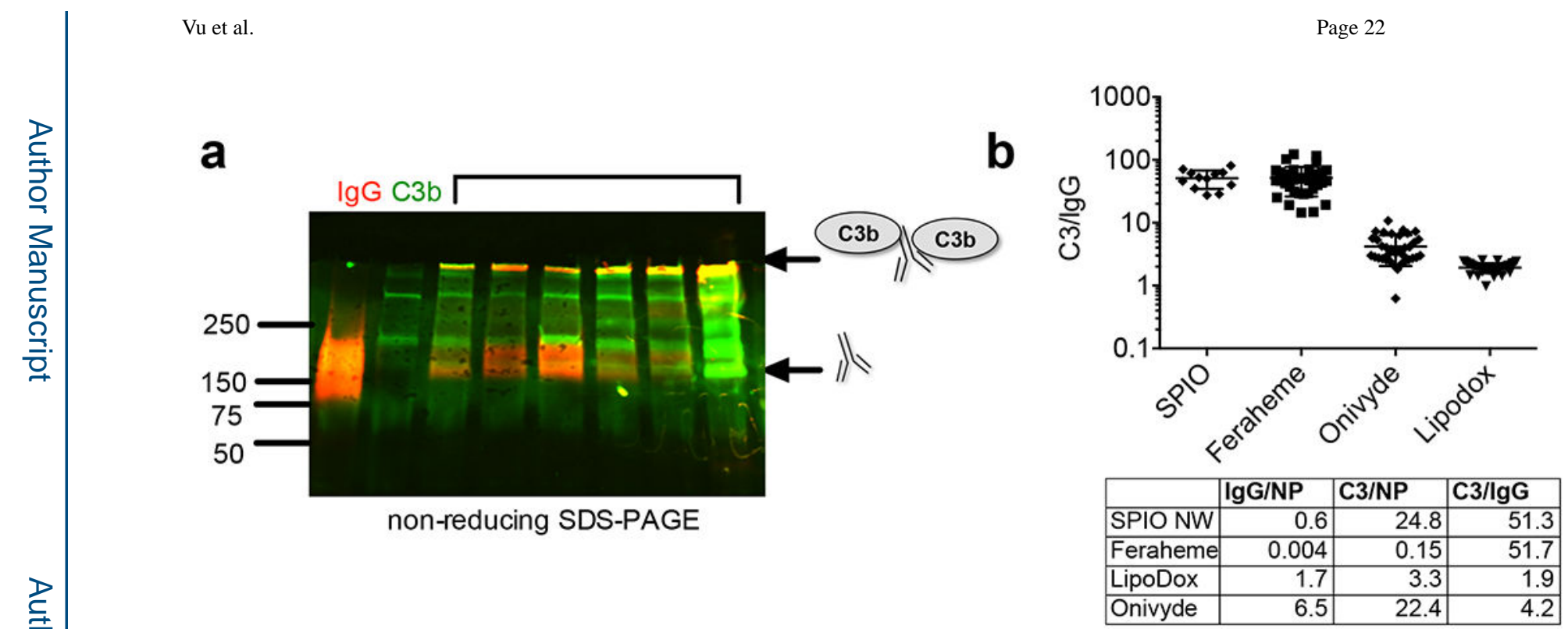

Fig. 4. Association between immunoglobulin and $\mathrm{C} 3$ in the protein corona:

a) protein corona formed on SPIO NWs (6 healthy donor sera) was eluted with $2 \%$ SDS and analysed on a non-reducing SDS-PAGE. The membrane was probed with anti-C3 (IRDye 800, green) and anti-IgG (IRDye 680, red). IgG-C3 complexes in high molecular weight fraction are shown with upper arrow. Free $\mathrm{IgG}$ is shown with lower arrow. $\operatorname{IgG}$ and $\mathrm{C} 3 \mathrm{~b}$ standards were run in parallel (left 2 lanes). Note the presence of several high molecular weight bands for $\mathrm{C} 3$, suggesting binding to other corona proteins. The bulk of $\mathrm{C} 3$ is not bound to IgG. Note that in the rightmost lane there are more IgG-C3 complexes and also more total C3, whereas the leftmost serum lane shows the opposite. The experiment was repeated 3 times in serum and once in plasma (Supplementary Fig. S7); b) stoichiometry calculations show more C3 than IgG molecules bound per nanoparticle. Feraheme ${ }^{\circledR}$ shows the highest ratio, whereas LipoDox ${ }^{\circledR}$ shows the lowest ratio. Note that for Feraheme ${ }^{\circledR}$ not every nanoparticle contains $\mathrm{C} 3$ and $\mathrm{IgG}$ molecules. For other nanoparticle types, there are few IgG molecules per nanoparticle. The results represent means \pm SD of $n=12$ sera for every nanoparticle type. Each dot represents the mean of 3 technical replicates. 


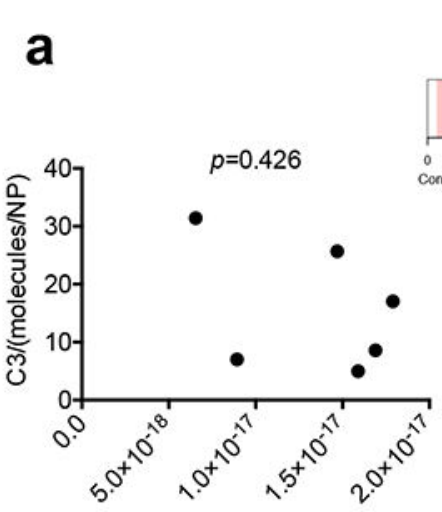

Non-C3 protein/NP (g)
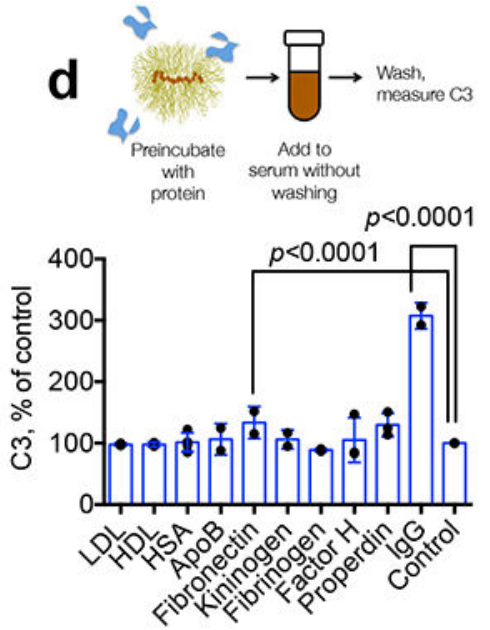
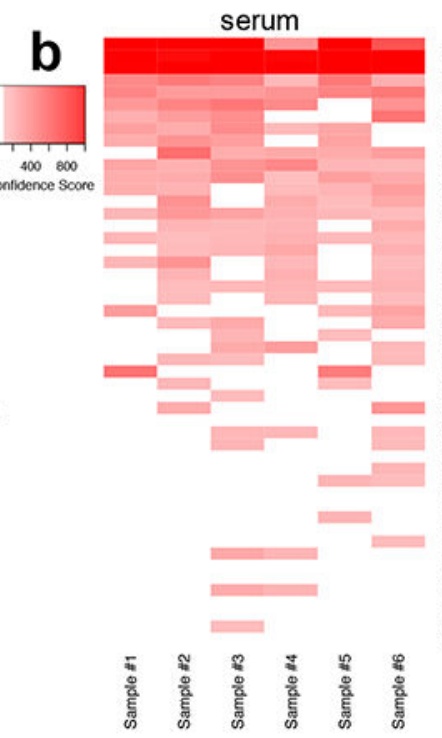

e
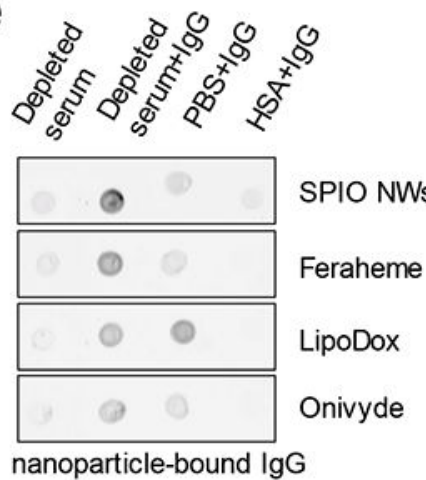

plasma

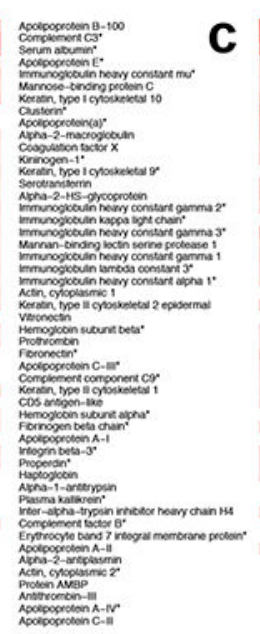

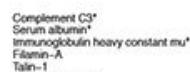
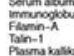

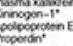

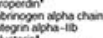

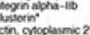

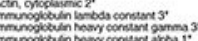

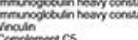

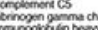

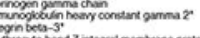

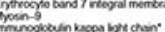
i. -3 .

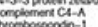

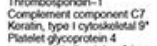

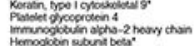

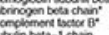

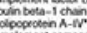

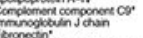

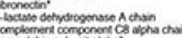

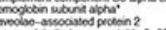

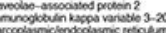

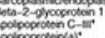

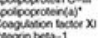

Fig. 5. Role of biomolecule corona in $\mathrm{C} 3$ and IgG deposition;

a) lack of correlation between the amount of total absorbed (non-C3) protein and $\mathrm{C} 3$ on SPIO NWs in sera ( $\mathrm{n}=6$ subjects, repeated 3 times, Pearson correlation, two-sided $t$-test); b) heat map of top 50 proteins identified in coronas formed on SPIO NWs in sera ( $n=6$ subjects); c) Heat map of top 50 proteins identified in coronas formed on SPIO NWs in plasma ( $n=5$ subjects). Proteins are ranked by the confidence score determined by the number of peptides (coverage) and the quality of the MS spectra. The asterisk indicates that the protein was identified within the top 50 of both serum and plasma samples; d) some of the proteins and lipoproteins identified with proteomics were preincubated with nanoparticles and the latter were added to sera without washing. Percent change relative to buffer-preincubated particles is shown. C3 deposition was significantly increased $(p<0.0001)$ after preincubation with $\operatorname{IgG}$ and fibronectin. ( $n=3$ sera, each dot is the mean value and SD of 3 technical replicates); e) a representative dot blot showing nanoparticle binding of purified polyclonal IgG added either to protein A-depleted serum or PBS or $50 \mathrm{mg} / \mathrm{mL}$ human serum albumin (HSA). Final IgG concentration was $5.5 \mathrm{mg} / \mathrm{mL}$ in all samples. The experiment was reproduced 2 times.; f) densitometry quantification (integrated density) of 
binding of IgG to SPIO NWs, Feraheme ${ }^{\circledR}$ and Onivyde ${ }^{\circledR}$ shows that protein corona enhances IgG binding compared with PBS or HSA. LipoDox ${ }^{\circledR}$ showed significant binding in PBS and depleted sera, but no binding in presence of HSA. Residual IgG binding in depleted sera was subtracted from IgG-reconstituted sera to obtain the "depleted serum + IgG" value. Labels designate serum samples. $M=$ male, number=age. Bars show mean values and SD of 3 technical replicates. The experiment was repeated twice. Statistical analysis is explained in Methods. 


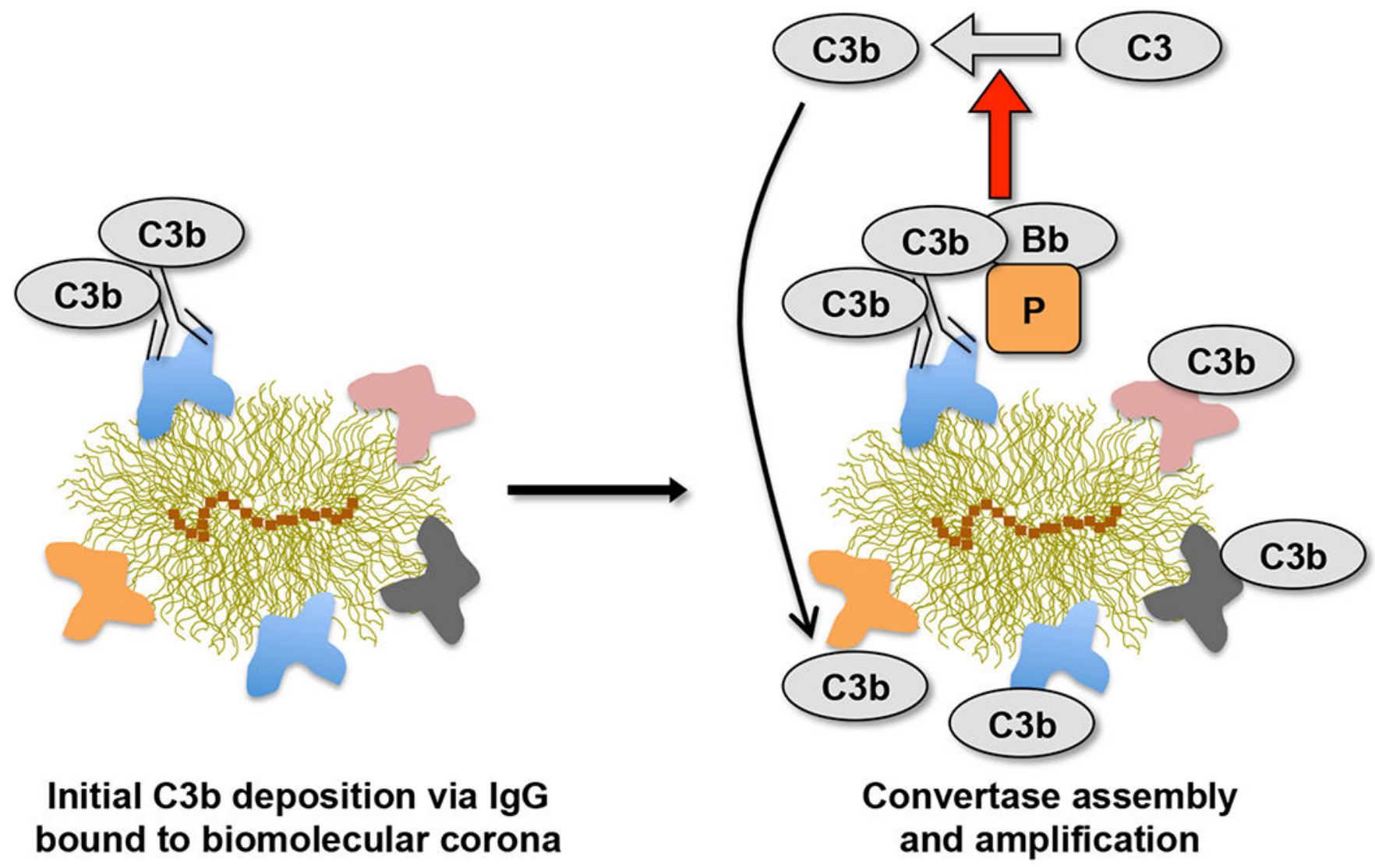

Fig. 6. Proposed scheme of the role of biomolecule corona and immunoglobulin in activation of the alternative pathway:

IgG binds to the biomolecule corona and then attacked by spontaneously formed (nascent) $\mathrm{C} 3 \mathrm{~b}$ molecules. Alternatively, IgG-C3b complexes are formed in fluid phase prior to binding of $\mathrm{IgG}$ to biomolecule corona of the nanoparticle. The deposition of $\mathrm{C} 3 \mathrm{~b}$ leads to formation of $\mathrm{C} 3 \mathrm{bBbProperdin}$, cleavage of serum $\mathrm{C} 3$ and deposition of additional $\mathrm{C} 3 \mathrm{~b}$ molecules on nanoparticle corona proteins (amplification). In addition to $\mathrm{IgG}$, other immunoglobulin types may potentially trigger the process. 